\title{
Flipped Classroom : Model Pembelajaran untuk Mencapai Kecakapan Abad 21 Sesuai
} Kurikulum 2013

\author{
Yuniar Adhinaya Yulianti ${ }^{* 1}$, Dwi Wulandari ${ }^{2}$ \\ ${ }^{*}$ Pendidikan Ekonomi, Pascasarjana, Universitas Negeri Malang \\ ${ }^{2}$ Ekonomi dan Studi Pembangunan, Fakultas Ekonomi dan Bisnis, Universitas Negeri Malang \\ *Corresponding Author. Email: adhinayayuniar@gmail.com
}

\begin{abstract}
This study aims to analyze the suitability of the 21 st-century learning methods, namely the flipped classroom method with the curriculum applied in Indonesia, the 2013 curriculum. The method used in this research is qualitative with a literature review as a data technique. Data collection was carried out by reviewing the relevant literature as the primary object. This study using descriptive qualitative analysis techniques. From the result of the literature study, it can be concluded that learning reverses the class according to the principles of learning in the 2013 curriculum. This can be seen from its application which is more student-centered. Besides, warning activities, asking questions, gathering information, associating and analyzing, and communicating can be implemented in flipped classroom learning based on the application of technology in it, so that students will have skills according to the 21 st century.
\end{abstract}

\begin{abstract}
Abstrak: Penelitian ini bertujuan untuk menganalis kesesuaian antara metode pembelajaran abad 21 yaitu flipped classroom dengan kurikulum 2013 yang diterapkan di Indonesia. Metode yang digunakan dalam penelitian ini adalah kualitatif dengan kajian pustaka sebagai teknik pengumpulan data. Pengumpulan data dilakukan dengan mengkaji literatur-literatur yang relevan sebagai objek primer. Analisis data dalam penelitian ini menggunakan kualitatif deskriptif. Hasil penelitian ini menunjukkan bahwa pembelajaran flipped classroom sesuai dengan prinsip pembelajaran pada kurikulum 2013. Hal ini dapat dilihat dari proses penerapannya yang lebih berpusat pada siswa. Selain itu, kegiatan mengamati, menanya, mengumpulkan informasi, mengasosiasi dan menganalisis, serta mengkomunikasikan dapat diimplementasikan dalam pembelajaran flipped classroom dengan bauran pemanfaatan teknologi di dalamnya, sehingga siswa akan memiliki ketrampilan sesuai abad 21.
\end{abstract}

\section{Article History}

Received: 08-12-2020

Revised: 13-02-2021

Accepted: 15-03-2021

Published: 07-06-2021

\section{Key Words:}

Flipped Classroom, 21st-Century Learning, The 2013 Curriculum.

\section{Sejarah Artikel}

Diterima: 08-12-2020

Direvisi: 13-02-2021

Disetujui: 15-03-2021

Diterbitkan: 07-06-2021

\section{Kata Kunci:}

Flipped Classroom,

Kurikulum 2013,

Pembelajaran Abad 21.

How to Cite: Yulianti, Y., \& Wulandari, D. (2021). Flipped Classroom : Model Pembelajaran untuk Mencapai Kecakapan Abad 21 Sesuai Kurikulum 2013. Jurnal Kependidikan: Jurnal Hasil Penelitian dan Kajian Kepustakaan di Bidang Pendidikan, Pengajaran dan Pembelajaran, 7(2), 372-384. doi:https://doi.org/10.33394/jk.v7i2.3209

https://doi.org/10.33394/jk.v7i2.3209

This is an open-access article under the CC-BY-SA License.

\section{Pendahuluan}

Abad 21 merupakan abad yang ditandai dengan dahsyatnya perkembangan teknologi. Perkembangan teknologi yang begitu pesat tentunya mempengaruhi segala bidang termasuk pendidikan. Di bidang pendidikan, pengaruh teknologi terletak pada proses pembelajaran yang dikenal dengan sebutan pembelajaran abad 21. Konsep pendidikan Abad 21 sangat penting untuk dikembangkan karena jika dilihat dari peta persaingan dunia kerja yang semakin ketat tentunya tidak cukup apabila siswa hanya dibekali dengan kemampuan kognitif saja (Ariyanto et al., 2020). Pembelajaran abad 21 sendiri mengandung keterampilan berpikir kritis dan pemecahan masalah, kreativitas dan inovasi, kolaborasi, dan komunikasi yang harus dimiliki peserta didik agar mampu menghadapi tantangan masa depan (Redhana, 2019). Hal ini sejalan dengan pendapat (Mastura et al., 2010) bahwa keterampilan abad 21 sangat 
diperlukan dalam pembelajaran agar siswa dapat menyelesaikan berbagai masalah di masa depan dengan berpikir kreatif dan memiliki berbagai ide dari berbagai sumber dengan adanya teknologi.

Selain keterampilan berpikir kritis dan pemecahan masalah, kreativitas dan inovasi, kolaborasi, dan komunikasi, siswa maupun pendidik juga harus memiliki keterampilan pada bidang teknologi. Seperti yang kita ketahui bahwa di era saat ini, semua telah memasukkan teknologi di berbagai aspek. Implikasi pada pembelajaran di sekolah-sekolah di Indonesia mengharuskan semua stakeholder pendidikan harus menguasai ICT literacy skill. Guru, siswa, bahkan orangtua siswa harus melek teknologi dan media komunikasi, sehingga dapat melakukan komunikasi yang efektif, berpikir kritis, dapat memecahkan masalah dan bisa berkolaborasi. Keterampilan abad 21 merupakan ketrampilan digital dimana memanfaatkan Teknologi Informasi dan Komunikasi (TIK) sepenuhnya untuk memenuhi tuntutan pekerjaan (Laar et al., 2017).

Adanya dampak penggunaan teknologi yang semakin pesat, diharapkan mampu mencapai hasil belajar sesuai pendidikan abad 21. Hasil belajar peserta didik pada pembelajaran abad 21 adalah ketrampilan belajar dan inovasi, ketrampilan informasi, media, dan teknologi, ketrampilan hidup dan karir, ketrampilan sosial dan lintas budaya, serta kepemimpinan dan tanggung jawab (Redhana, 2019). Untuk mencapai hasil belajar sesuai dengan yang diharapkan pada pembelajaran abad 21, tentunya tidak terlepas dari peran seorang guru. Upaya yang dapat dilakukan seorang guru adalah dengan menerapkan metode pembelajaran yang sesuai dengan pembelajaran abad 21 yang mampu membuat suasana pembelajaran di kelas yang efektif. Pembelajaran abad 21 berbeda dengan pembelajaran sebelumnya yang cenderung berpusat pada guru. Pembelajaran saat ini harus menjadikan siwa sebagai peran utama. Guru hanya sebagai fasilitator. Hal ini sesuai dengan kurikulum yang berlaku di Indonesia dimana siswa diarahkan untuk melakukan pembelajaran saintifik sehingga siswa dapat mengembangkan keterampilan berpikir kritis dan pemecahan masalah, kreativitas dan inovasi, kolaborasi, dan komunikasi sesuai keterampilan abad 21.

Akan tetapi, masih ditemukan pelaksanaan pembelajaran yang kegiatannya berpusat pada guru. Siswa dituntut untuk mendengarkan dan menghafal materi pelajaran yang diberikan guru. Pembelajaran seperti ini menyebabkan siswa tidak mampu menyusun pengetahuan dan keterampilannya sendiri, sehingga dapat menjadikan siswa belum memiliki ketrampilan sesuai abad 21. Seyogyanya kegiatan pembelajaran menggunakan pendekatan yang berpusat pada siswa. Siswa ditempatkan sebagai subyek pembelajaran yang secara aktif mengembangkan minat dan potensi yang dimilikinya. Sehingga mereka berupaya mengkonstruksi pengetahuan dan keterampilannya, sesuai dengan kapasitas dan tingkat perkembangan berfikirnya, diarahkan berkontribusi untuk memecahkan masalah-masalah nyata yang terjadi di masyarakat. Banyak sekali pilihan model pembelajaran yang dapat diterapkan. Model pembelajaran Flipped classroom adalah salah satu upaya untuk memberi solusi permasalahan yang dapat diterapkan dalam menghadapi pendidikan abadi 21 ini.

Flipped classroom adalah model pembelajaran dimana siswa memperoleh materi melalui video yang disampaikan di luar kelas dan kemudian melakukan dikusi, pemecahan masalah bahkan debat terhadap materi tersebut ketika berada di kelas (Billings, 2016). Model pembelajaran Flipped classroom ini memanfaatkan media pembelajaran yang dapat diakses secara online oleh siswa yang mampu mendukung materi pembelajarannya (Maolidah et al., 2017). Penerapan flipped classroom pada kegiatan pembelajaran sesuai dengan kurikulum 2013 dimana kegiatan pembelajaran lebih berpusat pada siswa sehingga siswa dapat mengembangkan keterampilan 4C. Pembelajaran berpusat pada siswa akan menyebabkan terjadinya perbedaan pendapat sehingga akan membuat siswa lebih kuat dalam menemukan 
solusi dan dapat meningkatkan partisipasi dalam memecahkan masalah dan dapat meningkatkan keterampilan sosial, berbicara, mendengarkan, dan keterampilan memecahkan masalah secara logis (Asoodeh et al., 2012).

Adapun tujuan penelitian ini adalah untuk menganalisis pembelajaran flipped classroom sebagai salah satu strategi pembelajaran yang dapat diterapkan pada kegiatan pembelajaran di Indonesia untuk mencapai kecakapan abad 21.

\section{Metode Penelitian}

Metode yang digunakan dalam penelitian ini adalah kualitatif dengan teknik pengumpulan data yang bersifat kepustakaan. Adapun sumber data yang digunakan sebagai pengumpulaan data antara lain jurnal ilmiah yang terindeks Sinta, jurnal internasional terindeks Scopus, blog pembelajaran dari Kementrian Pendidikan dan Kebudayaan, serta hasil-hasil penelitian yang relevan dengan tema yang dibahas pada artikel ini. Teknik analisis data yang digunakan yaitu kualitatif deskriptif, sehingga data yang diperoleh dari hasil kajian kepustakaaan akan dianalisis, diringkas, dan digambarkan terkait permasalahan yang diteliti.

\section{Hasil Penelitian dan Pembahasan Pembelajaran Abad 21}

Pembelajaran abad 21 merupakan pembelajaran yang mempersiapkan generasi abad 21 dimana kemajuan Teknologi Informasi dan Komunikasi (TIK) memiliki pengaruh yang begitu pesat pada kegiatan pembelajaran. Pengaruh TIK pada pembelajaran menuntut siswa maupun guru untuk menguasai teknologi sehingga memiliki ketrampilan dalam penggunaan teknologi. Teknologi memiliki peran dalam masyarakat maupun dalam kelas dan teknologi dapat digunakan sebagai alat dalam kegiatan pembelajaran yang mendalam (Ontario's, 2015). Menurut kemendikbud, ciri abad 21 adalah mudahnya mengakses informasi, penggunaan komputasi, mudahnya menjangkau pekerjaan, dan mudahnya berkomunikasi (Tim \& Widjajanti, n.d.). Pada pembelajaran abad 21, keterampilan digital dimana memanfaatkan Teknologi Informasi dan Komunikasi (TIK) sepenuhnya untuk memenuhi tuntutan pekerjaan (Laar et al., 2017).

Pembelajaran abad 21 sebaiknya disusun sesuai perkembangan zaman agar para siswa memiliki keterampilan-keterampilan abad 21. Proses kegiatan pembelajaran abad 21 dirancang agar kegiatan belajar pembelajaran berpusat pada siswa (student-centered) dan guru tidak lagi menjadi pusat pemberi pemelajaran, melainkan hanya sebagai fasilitator (Rafianti, I et al 2018). Upaya mengembangkan keterampilan abad 21 dapat dilkukan dengan merubah kegiatan pembelajaran menjadi student-centered learning (Redhana, 2019). Kegiatan pembelajaran abad 21 adalah belajar berdasarkan dunia nyata, otentik melalui proyek dan permaslahan, inkuiri, discovery, dan invensi dalam praktik abad pengetahuan (Tim \& Widjajanti, n.d.). Menurut Kemendikbud Indonesia terjadi pergeseran paradigma pembelajaran abad 21 seperti dalam tabel berikut;

Tabel 1. Pergeseran Paradigma Pembelajaran Abad 21

\begin{tabular}{ll}
\hline Ciri Abad 21 & Model Pembelajaran \\
\hline INFORMASI & Pembelajaran diarahkan untuk mendorong peserta \\
Tersedia di mana saja, kapan saja & didik mencari tahu dan berbagi dan berbagi \\
& sumber observasi bukan diberi tahu \\
KOMPUTASI & $\begin{array}{l}\text { Pembelajaran diarahkan untuk mampu } \\
\text { merumuskan masalah (bertanya), bukan hanya } \\
\text { Lebih cepat memakai mesin }\end{array}$ \\
& menyelesaikan masalah (menjawab)
\end{tabular}




\section{OTOMASI}

Menjangkau semua pekerjaan rutin
Pembelajaran diarahkan untuk melatih berfikir analitis (pengambilan keputusan) bukan berfikir mekanistis (rutin)

Pembelajaran menekankan pentingnya kerjasama /kolaborasi dalam menyelesaikan masalah.

\section{Dari mana saja, kemana saja}

Litbang Kemendikbud (2013) (Tim \& Widjajanti, n.d.)

Tidak hanya ketrampilan teknologi, pada pembelajaran abad 21 juga harus memiliki keterampilan hidup dan karir serta ketrampilan inovasi dan pembelajaran (critical thinking, creativity, collaboration, and communication) (Series 2019; Ongardwanich, Kanjanawasee, and Tuipae 2015); Qian and Clark 2016). "The skills that will form the basis for 21 st century curricula emphasize communication, collaboration, problem solving, citizenship, and digital fluency" (Dass, 2014). Ada empat hal yang harus dimiliki oleh generai abad 21 menurut Binkley (2012) yaitu ways of thinking, ways of working, tools for working and skills for living in the world (Rafianti, I et al. 2018). Pengembangan ketrampilan abad 21 harus memberikan arti bagi kehidupan agar siswa dapat beradaptasi, berinisiatif, memiliki ketrampilan sosial budaya, produktif, dan memiliki jiwa kepemipinan serta bertanggung jawab (Ongardwanich et al., 2015). Banyak sekali keterampilan yang diperlukan di abad 21 diantaranya kemampuan menerapkan pengetahuan yang diperoleh guna menghadapi tantagan kehidupan di masa depan (Mastura et al., 2010).

\section{Flipped Classroom}

Flipped classroom atau yang dikenal dengan kelas terbalik adalah proses belajar mengajar yang menggunakan aspek teknologi pada prosesnya. Penerapan flipped classroom ini adalah dengan membalik kegiatan pembelajaran yang dilakukan di sekolah menjadi dilakukan di rumah begitu pula sebaliknya (Nurpianti et al., n.d.). Model pembelajaran flipped classroom merubah pembelajaran tradisional dari yang awalnya menjadi rutinitas guru memberikan materi di kelas kemudian dirubah memberikan tugas untuk dikerjakan di kelas dan di luar kelas (Rindaningsih, 2018),. Jantung dari flipped classroom adalah "mentransfer" materi diluar kelas formal melalui video atau catatan yang sesuai dan menggunakan kelas formal untuk berkolaborasi dan melakukan kegiatan yang relevan (Butt, 2014). Berbeda dengan pembelajaran tradisional, flipped classroom merubah pembelajaran siswa aktif menjadi kegiatan pembelajaran pengalaman dan materi pembelajaran disediakan menggunakan alat digital (Foster \& Stagl, 2018). Penggunaan waktu di kelas antara pembelajaran tradisional dan flipped classroom juga berbeda. Perbedaan alokasi waktu dalam kelas dan kegiatannya disajikan dalam tabel berikut:

Tabel 2. Perbedaan Alokasi Waktu dan Aktivitas di Kelas Tradisional dengan Flipped classroom

\begin{tabular}{|c|c|c|c|}
\hline \multicolumn{2}{|l|}{ Kelas Tradisional } & \multicolumn{2}{|l|}{ Flipped classroom } \\
\hline Aktivitas & Waktu & Aktivitas & waktu \\
\hline Kegiatan pendahuluan & 5 menit & Kegiatan pendahuluan & 5 menit \\
\hline Pembahasan tugas sebelumnya & 20 menit & $\begin{array}{l}\text { Tanya jawab terkait materi } \\
\text { pembelajaran yang terdapat } \\
\text { video }\end{array}$ & $\begin{array}{c}10 \\
\text { menit }\end{array}$ \\
\hline Menjelaskan materi baru & $\begin{array}{l}30-45 \\
\text { menit }\end{array}$ & $\begin{array}{l}\text { Memandu dan melakukan kegiatan } \\
\text { praktek atau kegiatan di laboratorium }\end{array}$ & $\begin{array}{c}75 \\
\text { menit }\end{array}$ \\
\hline $\begin{array}{l}\text { Memandu dan melakukan } \\
\text { kegiatan praktek atau kegiatan } \\
\text { di laboratorium }\end{array}$ & $\begin{array}{l}20-35 \\
\text { menit }\end{array}$ & & \\
\hline
\end{tabular}

(Bergmann \& Sams, 2012) 
Ada empat pilar utama yang harus diterapkan guru dalam pembelajaran kelas terbalik menurut (Nurpianti et al., n.d.) yaitu, guru memberikan kesempatan siswa untuk berinteraksi merefleksikan hasil belajarnya (Flexible Environment), siswa diberikan kebebasan penuh sebagai pusat dalam kegiatan pembelajaran (Learning Culture Shift), pada pilar ini guru membuat materi pembelajaran yang dapat diakses oleh siswa dimanapun berada (Intentional Content), dan pilar tearkhir ini mengharuskan guru untuk membuat dirinya selalu siap sedia untuk setiap siswa secara individual, grup kecil, atau feedback kelas pada waktu di kelas, melibatkan penilaian formatif selama kelas belangsung dengan melakukan observasi dan merekam data untuk menginformasikan instruksi masa depan, dan bertanggung jawab untuk melakukan perubahan (Professional Educators).

Menurut (He et al., 2016) terdapat tiga komponen utama dalam instruksi pelaksanaan kelas terbalik atau flipped classroom adalah (1) Pre-Class Learning, pada atribut ini instruksi ditujukan untuk mengajar pengetahuan secara faktul sebelum berada di kelas dan pengetahuan yang diajarkan hanya diulas secara singkat, (2) In-Depth Explanation, Practice, and Productive Use Of Knowledge In Class Through Active Learning Techniques, pada intruksi ini, pengetahuan harus digunakan seproduktif mungkin agar tumbuh menjadi kelas yang aktif dan semua menjadi paham, (3) Class Attendance, pentingnya kehadiran siswa di kelas.

Dengan menerapkan flipped classroom, siswa diharapkan untuk melakukan pembelajaran secara mandiri melalui konten digital yang diberikan guru sehingga di kelas mereka memiliki banyak waktu untuk melakukan dikusi (Rindaningsih et al., 2019). Sementara itu, dengan belajar mandiri melalui video siswa akan menjadi bertanggung jawab atas proses belajar mereka sendiri dan haru mengatur pembelajaran mereka sendiri (Lai dan Hwang, 2016 dalam (Akçayır \& Akçayır, 2018). Peningkatan produktivitas pembelajaran pada penerapan kelas terbalik terlihat dari banyaknya siswa yang mengajukan pertanyaan baik ketika di luar maupun di dalam kelas (Yamarik, 2019). Secara keseluruhan, flipped classroom disediakan lebih banyak kesempatan bagi siswa untuk terlibat dalam berpikir kritis, mandiri memfasilitasi pembelajaran mereka sendiri, dan lebih efektif berinteraksi dengan dan belajar dari rekan-rekan mereka (Rindaningsih et al., 2019). Penerapan flipped classroom membantu guru menghabiskan waktu di kelas untuk melakukan pendekatan pembelajaran yang berpusat pada siswa seperti melakukan diskusi kelompok dan memberikan tugas mandiri sehingga dapat merubah kebiasaan belajar siswa dan meningktakan kemampuan komunikasi siswa (Munir et al., 2018).

Beberapa alasan mengapa kita sebaiknya mempertimbangkan untuk menerapkan flipped classroom (Bergmann \& Sams, 2012) adalah (1) Di era teknologi seperti saat ini, siswa tumbuh dengan akses internet yang mudah sehingga perlu mengajarkan pada siswa bagaimana belajar dengan memanfaatkan teknologi (Flipping speaks the language of today's students); (2) Flipping helps struggling student, dalam menerapkan flipped classroom guru dapat membantu semua murid yang kesusahan tanpa terkecuali dikarenakan seluruh perhatian tertuju pada siswa; (3) Flipping helps students of all abilities to excel, yaitu karena telah direkamnya materi pembelajaran, siswa dapat mengulang materi pembelajaran sesuai dengan yang mereka kehendaki sehingga mereka dapat memahami materi dengan mudah; (4) Flipping increases student-teacher interaction, dengan adanya perpaduan antara instruksi online dan belajar di kelas menyebabkan adanya peningkatan interaksi antara siswa dan guru; (5) Flipping increases student-student interaction, yaitu meeningkatnya interaksi siswa dengan siswa yang disebabkan oleh berubahnya peran guru menjadi fasilitator dalam penerapan flipped classroom membuat siswa mengembankan kelompok kolaboratifnya sendiri sehingga mereka dapat belajar dari satu sama lain; dan (6) Flipping changes 
classroom management, kegiatan pembelajaran di dalam kelas yang berpusat pada siswa menyebabkan siswa tidak akan mudah merasa bosan.

Selain hal positif dengan adanya penerapan flipped classroom, beberapa hal yang harus diperhatikan agar flipped classroom dapat berjalan dengan efektif diantaranya yaitu kualitas konten video pembelajaran yang harus dibuat semenarik mungkin dan ketersediaan teknologi para siswa karena dua hal ini memiliki dampak langsung bagi kegiatan pembelajaran (Akçayır \& Akçayır, 2018).

\section{Pembahasan}

Perkembangan tekologi yang begitu pesat memberikan dampak bagi dunia pendidikan dengan munculnya pembelajaran abad 21. Guru memiliki peran penting dalam pembelajaran abad 21 dikarenakan agar para siswa nantinya memiliki keterampilan abad 21. These "real world skills" include communication, collaboration and critical thinking, skills that are deemed crucial for people from different contexts, countries and cultures to interact in a borderless, networked and globalized world (Teo, 2019).

Menurut (Wijoyo, 2010) beberapa hal yang harus diperhatikan dalam mengembangkan pembelajaran abad 21 yaitu, (a) Guru sebagai perencana pembelajaran yang baik harus menyusun rancangan pembelajaran sedetail mungkin yang tertuang dalam RPP. Dalam penyusunan RPP, guru memadukan antara target yang dicapai dalam kurikulum nasional, pengembangan ketrampilan abad 21 atau karakter nasional serta pemanfaatan teknologi dalam kelas; (b) Dalam kegiatan pembelajaran harus memasukkan unsur berpikir kritis. Misalnya dalam pemberian tugas pada level aplikasi, analisa, evaluasi dan kreasi agar mendorong siswa untuk berpikir kritis dan memeriksa kebenaran informasi yang didapat terlebih dahulu sebelum menyelasikan tugas dari guru, sehingga mereka tidak hanya bertindak sebagai pengumpul informasi; (c) Mengaplikasikan pendekatan dan model pembelajaran yang beragam. Ada beberapa pendekatan pembelajaran yang dapat diterapkan dalam kegiatan pembelajaran untuk menambah pengalaman pembelajaran siswa seperti, pembelajaran berbasis proyek (Project Based Learning), pembelajaran berbasis keingintahuan (Inquiry Based Learning) serta model pembelajaran silang (jigsaw) maupun model kelas terbalik (Flipped classroom); (d) Di era teknologi seperti saat ini, sebaiknya guru dan siswa selalu melibatkan teknologi dalam kegiatan pembelajaran.

Untuk mewujudkan pembelajaran abad 21 salah satunya adalah dengan menerapkan pembelajaran yang bervariasi. Proses pembelajaran yang diterapkan di Indonesia diatur dalam standar proses pendidikan menurut Peraturan Menteri Pendidikan dan Kebudayaan Nomor 22 Tahun 2016 tentang Standar Proses Pendidikan Dasar dan Menengah dinyatakan bahwa proses pembelajaran pada satuan pendidikan diselenggarakan secara interaktif, inspiratif, menyenangkan, menantang, memotivasi peserta didik untuk berpartisipasi aktif, serta memberikan ruang yang cukup bagi prakarsa, kreativitas, dan kemandirian sesuai dengan bakat minat, dan perkembangan fisik serta psikologis peserta didik. Selain berdasarkan Peraturan Menteri Pendidikan dan Kebudayaan, kegiatan pembelajaran disesuaikan dengan kurikulum yang berlaku di Indonesia, kegiatan pembelajaran kurikulum 2013 meliputi kegiatan mengamati, menanya, mengumpulkan informasi, mengasosiasi, atau menganalisis, dan mengkomunikasikan yang terintegrasi dalam pembelajaran berpusat pada siswa.

Menurut (Rafianti et al., 2018) pembelajaran yang berpusat pada siswa harus memiliki karakter 4C yaitu, (1) Communication, dimana pada karakter ini siswa dituntut untuk menciptakan komunikasi yang efektif. Peserta didik diberikan kesempatan menggunakan kemampuannya untuk menyampaikan ide-idenya, baik itu pada saat berdiskusi 
dengan teman-temannya maupun ketika menyelesaikan masalah dari pendidiknya; (2) Collaboration, pada karakter ini siswa menunjukkan kemampuan untuk bekerjasama, ketrampilan kepemimpinan, beradaptasi dalam berbagai peran dan tanggungjawab, bekerja secara produktif dengan yang lain, menempatkan empati pada tempatnya, menghormati perspektif berbeda; (3) Critical thinking and Problem Solving, dimana siswa berusaha untuk memberikan penalaran yang masuk akal dalam memahami dan membuat pilihan yang rumit, memahami interkoneksi antara sistem. Siswa juga menggunakan kemampuan yang dimilikinya untuk berusaha menyelesaikan permasalahan yang dihadapinya dengan mandiri, peserta didik juga memiliki kemampuan untuk menyusun dan mengungkapkan, menganalisa, dan menyelesaikan masalah; (4) Creativity and Innovation yaitu peserta didik memiliki kemampuan untuk mengembangkan, melaksanakan, dan menyampaikan gagasan-gagasan baru kepada yang lain, bersikap terbuka dan responsif terhadap perspektif baru dan berbeda.

Melihat dari 4 karakter yang harus dimiliki pada kegiatan pembelajaran saat ini, salah satu model pembelajaran yang sesuai untuk meningkatkan ketrampilan abad 21 adalah flipped classroom. Flipped classroom adalah model pembelajaran yang membalik model pembelajaran tradisional. Biasanya siswa mendapatkan materi di kelas dan ketika di rumah siswa mengerjakan tugas yang di dapat dari sekolah, namun pada model pembelajaran flipped classroom kegiatan pembelajaran seperti ini dibalik. Seperti yang dikatakan (Bergmann \& Sams, 2012) bahwa konsep dasar flipped classroom adalah apa yang dilakukan di kelas sekarang dilakukan di rumah dan apa yang dilakukan sebagai pekerjaan rumah saat ini dikerjakan di kelas.

Model pembelajaran flipped clssroom ini mengaplikasikan teknologi sebagai media dalam pembelajaran. Prinsip penggunaan media sendiri adalah efektif dan efisien, membantu menyingkat waktu penyampaian materi ajar dan dapat merangsang imajinasi pendidik saat mendapatkan informasi faktual melalui media (Budiyono, 2020). Hal ini sesuai dengan ciri pada pembelajaran abad 21 di mana siswa maupun guru harus memiliki kecakapan penggunaan teknologi. Pengaplikasian teknologi yang dimaksud adalah penggunaan video atau media lainnya sebagai konten pembelajaran untuk dipelajari siswa di rumah sebelum melakukan kegiatan tatap muka di kelas. Hal ini seperti yang diungkapkan (van Alten et al., 2019) bahwa mereka mendefinisikan bahwa para siswa pada pembelajaran flipped classroom akan menyiapkan materi sebelum pelaksanaan pembelajaran dikelas misalnya melalui tontonan video ceramah. Flipped classroom mendorong siswa untuk belajar mandiri melalui link materi pelajaran yang sudah dibangun guru dalam web berupa video online sebelum datang ke kelas (Rindaningsih et al., 2019). Selama menggunakan flipped classroom, guru merancang konten digital, yang berupa gabngan video rekaman dan membaca atau berupa rangkaian video pendek yang diertai dengan membaca dan kuis di dalamnya. (Munir et al., 2018). (O'Flaherty \& Phillips, 2015) juga menyarankan agar kegiatan perkuliahan direkam sehingga para siswadapat memutarnya ketika berada di luar kelas, dengan begitu mereka bisa mengatur kecepatan belajar mereka sendiridan memungkinkan mereka memiliki flekibilitas dengan adanya sumber daya elektronik.

Komponen yang harus diperhatikan dalam mengimplementasikan flipped clasroom salah satunya adalah video yang berisi materi pembelajaran. Guru dapat membuat video pembelajaran sendiri atau menggunakan video dari internet sebagai media pembelajaran. Video yang diberikan kepada siswa untuk dipelajari sebelum kegiatan pembelajaran di kelas harus didesain semenarik mungkin dan tentunya harus mengedukasi agar siswa mudah memahami materi yang akan didiskusikan. Menurut (Bergmann \& Sams, 2012) video yang baik adalah sebagai berikut: video yang tidak terlalu panjang, hidupkan suara anda, mengikutsertakan guru lain dalam konten video, menambahkan humor, tidak menghabiskan 
waktu para siswa dengan membahas topik yang lain, tambahkan anotasi, info, dan sertakan copyright. Konten video menjadi salah satu komponen penting yang perlu diperhatikan karena berkaitan langsung dengan kegiatan pembelajaran.

Model pembelajaran flipped classroom dapat di design dan diterapkan dengan mengkombinasi beberapa kegiatan pembelajaran lainnya. Beberapa penelitian menggabungkan flipped classroom dengan pendekatan, metode, maupun model pembelajaran seperti menggabungkan flipped classroom dengan pembelajaran cooperative, course review horay, peer instruction, problem based learning, collabortive learning, dan experiential learning (Munir et al., 2018); (Agustiningrum \& Haryono, 2017); (Adhitiya, 2015); (Foster \& Stagl, 2018). Hasil penelitian (Chiang, 2017) menunjukkan bahwa pembelajaran flipped classroom yang dikombinasi dengan strategi pemecahan masalah lebih efektif dibanding model lama dari pembelajaran pemecahan masalah.

Adapun langkah-langkah pembelajaran flipped classroom menurut Steele (2013) dalam (Adhitiya, 2015) adalah siswa diminta untuk menonton video pembelajaran atau media lainnya di rumah sebagai persiapan sebelum mengikuti keitn pembelajran di kelas (preclass). Kemudian siswa datang ke kelas untuk melakukan kegiatan pembelajaran dengan mengerjakan tugas yang berkaitan dengan bahan ajar yang telah dipelajari sebelumnya. Ketika di kelas siswa menerapkan kemampuan dalam proyek ataupun simulasi lainnya. Kegiatan terakhir adalah pengukuran pemahaman siswa terkait materi yang telah diajarkan.

Dilihat dari langkah-langkah penerapan model flipped classroom, model ini merupakan model yang sesuai dengan langkah-langkah pada prinsip pembelajaran kurikulum 2013. Pada tahap mengamati terjadi ketika siswa mengamati konten video pembelajaran yang ditonton di rumah sebelum kegiatan pembelajaran di kelas berlangsung. Setelah menonton video, siswa akan timbul pertanyaan mengenai materi yang akan dipelajari. Sehingga mereka akan mengumpulkan informasi terkait topik pembelajaran terebut sebagai bahan untuk mempersiapkan kegiatan belajar di kelas. Ketika siswa melakukan pembelajaran di kelas, siswa dapat mengasosiasi, atau menganalisis permasalahan atau soal yang diberikan oleh guru lalu mengkomunikasikannya melalui sebuah diskusi dalam kelas. Pembelajaran ini banyak melibatkan siswa dalam setiap prosesnya. Sehingga siswa menjadi aktif. Sesuai dengan hasil penelitian (Elmaadaway, 2018) bahwa pada kelas eksperimen yang diberikan perlakuan melalui flipped classroom lebih aktif dibandingkan dengan kelas kontrol yang diberikan perlakuan pembelajaran tradisional.

Dengan memerhatikan komponen penting dan langkah-langkah pembelajaran flipped classroom dengan benar, guru akan mengalami keberhasilan saat menerapkan model pembelajaran ini. Keberhasilan penerapan flipped classroom akan menyebabkan para peserta didik mencapai hasil belajar yang maksimal sehingga memiliki keterampilan abad 21. Hal ini sesuai dengan hasil penelitian (Agustiningrum \& Haryono, 2017) bahwa hasil belajar kognitif siswa mengalami peningkatan setelah menerapkan model pembelaran flipped clasroom dan course review horay. Peningkatan hasil belajar disebabkan oleh beberapa faktor, terutama kualitas pengajaran dan lingkungan belajar siswa. Penggunaan model flipped classroom menyebabkan peningkatan aktivitas di kelas hal ini ditandai dengan sebagian besar siswa aktif menyampaikan pendapatnya dalam kegiatan diskusi kelas. Menurut (Abeysekera \& Dawson, 2015) lingkungan belajar pada pendekatan flipped clssroom cenderung memuaskan siswa pada kebutuhan kompetensi, otonomi, dan keterkaitan sehingga meningkatkan motivasi intriksik dan ekstrinsik sehingga mempengaruhi keterlibatan siswa pada lingkungan pembelajaran flipped classroom. (Awidi \& Paynter, 2019) juga mengatakan bahwa komponen-komponen pembelajaran flipped classroom mempengaruhi tingkat kepuasan dan 
tingkat keterlibatan siswa dalam kegiatan di kelas sehingga dapat menambah pengalaman belajar.

Selain meningkatkan hasil belajar dan aktivitas di lingkungan kelas, flipped classroom juga dapat meningkatkan kemampuan berpikir kritis siswa. Hal ini sesuai dengan hasil penelitian (Maolidah et al., 2017). Hasil penelitian (Foster \& Stagl, 2018) juga menunjukkan bahwa dengan menerapkan flipped classroom mennyebabkan keterampilan berpikir kreatif dan ketrampilan komunikasi lebih tinggi dibandingkan ketrampilan lain. Penelitian (Kong, 2014) juga mengatakan bahwa dengan menerapkan flipped classroom dapat memupuk literasi informasi dan kemampuan berpikir kritis siswa. Saat melakukan flipped classroom dapat dilakukan interaksi antara guru dengan siswa dalam mempromosikan kreativitas, dan memungkinkan cara terbaru dalam berpikir kritis dan memecahkan masalah (Roehl et al., 2013). (Rindaningsih et al., 2019) juga menyimpulkan bahwa flipped classroom memberikan lebih banyak kesempatan bagi siswa untuk terlibat dalam berpikir kritis, mandiri memfasilitasi pembelajaran mereka sendiri, dan lebih efektif berinteraksi dengan dan belajar dari teman-temannya. Berdasarkan beberapa hasil penelitian tersebut, flipped classroom dapat dijadikan sebagai upaya dalam memenuhi keterampilan abad 21.

Manfaat dari penerapan model pembelajaran flipped classroom ini yaitu, (Yasin, n.d.), peserta didik memiliki kesempatan penuh untuk memahami arahan dan penjelasan dari guru secara mandiri ataupun kolaboratif di dalam ataupun di luar kelas secara online, guru dapat memastikan bahwa setiap peserta didik telah memahami materi-materi yang diajarkan di luar ataupun di luar kelas, dan peserta didik dapat meningkatkan kapasitas pembelajaran secara mandiri. Selain itu, terjalinnya komunikasi yang aktif antar peserta didik dan guru di luar ataupun di dalam kelas ketika pembelajaran.

Meski memiliki manfaat yang banyak dengan diterapkannya model pembelajaran flipped classroom, tetapi tetap saja ada kekurangan (Amiroh, n.d.) yaitu, tidak semua stakeholder sekolah memiliki akses yang memadai terhadap perangkat teknologi informasi yang dibutuhkan seperti laptop, komputer, dan akses internet. Bagi guru model ini membutuhkan waktu yang dikarenakan guru harus mempersiapkan materi dalam bentuk video, terutama guru yang belum terbiasa membuat video pembelajaran.

Selain kelemahan-kelemahan yang dialami oleh guru, siswa juga mengalami beberapa kendala dalam menerapkan model ini yaitu, beberapa siswa merasa tidak nyaman belajar menggunakan komputer atau laptop sedangkan syarat utama melaksanakan model pembelajaran flipped classrom mengharuskan siswa mengakses materi melalui perangkat tersebut dan rendahnya motivasi siswa untuk belajar secara mandiri di rumah terhadap materi yang belum disampaikan oleh guru. Oleh karena itu, meski model pembelajaran flipped classroom ini sesuai dengan kurikulum 2013 dan pembelajaran abad 21 guru juga harus memerhatikan kelemahan tersebut sebagai bahan pertimbangan dalam pemilihan model pembelajaran ini sehingga ketika diterapkan dapat berjalan maksimal.

\section{Kesimpulan}

Kesimpulan yang diperoleh dari hasil penelitian ini adalah Flipped classroom merupakan model pembelajaran di mana siswa mempelajari materi di rumah melalui video atau secara online kemudian ketika di kelas, siswa akan mengerjakan tugas. Model pemelajaran ini sesuai dengan prinsip pembelajaran kurikulum 2013 karena pada model flipped classroom kegiatan pembelajaran banyak melibatkan siswa dan guru hanya sebagai fasilitator. Sehingga dapat dikatakan bahwa pendekatan pembelajaran ini merupakan pembelajaran yang berpusat pada siswa (student-centered). Selain itu kegiatan mengamati, menanya, menumpulkan informasi, mengasosiasi dan menganalisis, serta mengkomunikasikan dapat 
diimplementasikan dalam pembelajaran flipped classroom. Flipped classroom terbukti dapat meningkatkan hasil belajar siswa. Selain hasil belajar, flipped classroom juga dapat meningkatkan kemampuan berpikir kritis, dan ketermpilan komunikasi seingga model ini dapat digunakan sebagai salah salah satu cara agar siswa memiliki keterampilan abad 21.

\section{Saran}

Hasil dari kajian kepustakaan ini diharapkan dapat menjadi bahan evaluasi atau pertimbangan bagi guru untuk menerapkan model pembelajaran flipped classroom dalam kegiatan pembelajaran sehingga mampu meningkatkan kemampuan siswa terutama dalam kecakapan abad 21 .

\section{Daftar Pustaka}

Abeysekera, L., \& Dawson, P. (2015). Motivation and cognitive load in the flipped classroom: definition, rationale and a call for research. Higher Education Research and Development, 34(1), 1-14. https://doi.org/10.1080/07294360.2014.934336

Adhitiya, E. N. (2015). Studi Komparasi Model Pembelajaran Traditional Flipped Dengan Peer Instruction Flipped Terhadap Kemampuan Pemecahan Masalah. Unnes Journal of Mathematics Education., 4(2). https://doi.org/10.15294/ujme.v4i2.7451

Agustiningrum, A., \& Haryono, A. (2017). Penerapan model pembelajaran flipped classroom dan course review horay berbasis lesson study untuk meningkatkan aktivitas dan hasil belajar siswa pada mata pelajaran ekonomi di kelas xi ips 2 man kota batu. 10(2), 111-120.

Akçayır, G., \& Akçayır, M. (2018). The flipped classroom: A review of its advantages and challenges. Computers and Education, 126(August), 334-345. https://doi.org/10.1016/j.compedu.2018.07.021

Amiroh. (n.d.). Kenapa Harus Flipped Classroom? - Media Belajar IT Siswa dan Guru. Retrieved March 24, 2020, from http://amiroh.web.id/kenapa-harus-flippedclassroom/

Ariyanto, S. R., Lestari, I. W. P., Hasanah, S. U., Rahmah, L., \& Purwanto, D. V. (2020). Problem Based Learning dan Argumentation Sebagai Solusi dalam Meningkatkan Kemampuan Berpikir Kritis Siswa SMK. Jurnal Kependidikan: Jurnal Hasil Penelitian Dan Kajian Kepustakaan Di Bidang Pendidikan, Pengajaran Dan Pembelajaran, 6(2), 197. https://doi.org/10.33394/jk.v6i2.2522

Asoodeh, M. H., Asoodeh, M. B., \& Zarepour, M. (2012). The Impact of Student - Centered Learning on Academic Achievement and Social Skills. Procedia - Social and Behavioral Sciences, 46, 560-564. https://doi.org/10.1016/j.sbspro.2012.05.160

Awidi, I. T., \& Paynter, M. (2019). The impact of a flipped classroom approach on student learning experience. Computers and Education, 128, 269-283. https://doi.org/10.1016/j.compedu.2018.09.013

Bergmann, J., \& Sams, A. (2012). Flipped Classroom As Innovative Practice in the Higher Education System: Awareness and Attitude. In 3rd International Multidisciplinary Scientific Conference on Social Sciences and Arts SGEM 2016, Book 1 (Vol. 3, Issue 
SGEM2016 Conference Proceedings, ISBN 978-619-7105-72-8 / ISSN 2367-5659). https://doi.org/10.5593/sgemsocial2016/B13/S03.043

Billings, D. M. (2016). "Flipping" the Classroom. American Journal of Nursing, 116(9), 5256. https://doi.org/10.1097/01.NAJ.0000494696.86240.35

Budiyono, B. (2020). Inovasi Pemanfaatan Teknologi Sebagai Media Pembelajaran di Era Revolusi 4.0. Jurnal Kependidikan: Jurnal Hasil Penelitian Dan Kajian Kepustakaan Di Bidang Pendidikan, Pengajaran Dan Pembelajaran, 6(2), 300. https://doi.org/10.33394/jk.v6i2.2475

Butt, A. (2014). Classroom Approach: Evidence From. Business Education, 6(1), 33-44.

Chiang, T. H. C. (2017). Analysis of learning behavior in a flipped programing classroom adopting problem-solving strategies. Interactive Learning Environments, 25(2), 189202. https://doi.org/10.1080/10494820.2016.1276084

Dass, R. (2014). Literature and the 21st Century Learner. Procedia - Social and Behavioral Sciences, 123, 289-298. https://doi.org/10.1016/j.sbspro.2014.01.1426

Elmaadaway, M. A. N. (2018). The effects of a flipped classroom approach on class engagement and skill performance in a Blackboard course. British Journal of Educational Technology, 49(3), 479-491. https://doi.org/10.1111/bjet.12553

Foster, G., \& Stagl, S. (2018). How effective is the Inverted Classroom Model ( ICM ), a teaching tool most SC. Journal of Cleaner Production. https://doi.org/10.1016/j.jclepro.2018.02.177

He, W., Holton, A., Farkas, G., \& Warschauer, M. (2016). The effects of flipped instruction on out-of-class study time, exam performance, and student perceptions. Learning and Instruction, 45, 61-71. https://doi.org/10.1016/j.learninstruc.2016.07.001

Kong, S. C. (2014). Developing Information Literacy and Critical Thinking Skills through Domain Knowledge Learning in Digital Classrooms: An Experience of Practicing Flipped Classroom Strategy. Computers \& Education. https://doi.org/10.1016/j.compedu.2014.05.009

Laar, E. Van, Deursen, A. J. A. M. Van, Dijk, J. A. G. M. Van, \& Haan, J. De. (2017). The relation between $21^{\text {st }}$-century skills and digital skills or literacy: A systematic literature review. The Relation between 21st-Century Skills and Digital Skills or Literacy A Systematic Literature Review. https://doi.org/10.1016/j.chb.2017.03.010

Maolidah, I. S., Ruhimat, T., \& Dewi, L. (2017). EFEKTIVITAS PENERAPAN MODEL PEMBELAJARAN FLIPPED. 3(2), 160-170.

Mastura, T., Soh, T., Mohamad, N., \& Osman, K. (2010). The Relationship of 21 st Century Skills on Students ' A ttitude and Perception towards Physics. 7(2), 546-554. https://doi.org/10.1016/j.sbspro.2010.10.073

Munir, M. T., Baroutian, S., Young, B. R., \& Carter, S. (2018). Flipped classroom with cooperative learning as a cornerstone. Education for Chemical Engineers, 1-9. https://doi.org/10.1016/j.ece.2018.05.001

Nurpianti, S., Suwarma, I. R., \& Jauhari, A. (n.d.). Kajian Implementasi Pendekatan Flipped Classroom pada Pembelajaran Fisika. 115-119. 
O'Flaherty, J., \& Phillips, C. (2015). The use of flipped classrooms in higher education: A scoping review. Internet and Higher Education, 25, 85-95. https://doi.org/10.1016/j.iheduc.2015.02.002

Ongardwanich, N., Kanjanawasee, S., \& Tuipae, C. (2015). Development of 21 st Century Skill Scales as Perceived by Students. Procedia - Social and Behavioral Sciences, 191, 737-741. https://doi.org/10.1016/j.sbspro.2015.04.716

Ontario's. (2015). Ontario's Draft 21st Century / Global Competencies Achieving Excellence: A Renewed Vision for Education in 21st Century Competencies Discussion Document: What We 've Learned. December, 53-56.

Qian, M., \& Clark, K. R. (2016). Computers in Human Behavior Game-based Learning and 21st century skills: A review of recent research. Computers in Human Behavior, 63, 50-58. https://doi.org/10.1016/j.chb.2016.05.023

Rafianti, I., Anriani, N., \& Iskandar, K. (2018). PENGEMBANGAN PERANGKAT PEMBELAJARAN MATEMATIKA. 3(1), 123-138.

Redhana, I. W. (2019). Mengembangkan Keterampilan Abad Ke-21 Dalam Pembelajaran Kimia. Jurnal Inovasi Pendidikan Kimia, 13(1).

Rindaningsih, I. (2018). Efektifitas Model Flipped Classroom dalam Mata Kuliah Perencanaan Pembelajaran Prodi S1 PGMI UMSIDA. Proceedings of the ICECRS, 1(3), 51-60. https://doi.org/10.21070/picecrs.v1i3.1380

Rindaningsih, I., Hastuti, W. D., \& Findawati, Y. (2019). Desain Lingkungan Belajar yang menyenangkan berbasis Flipped Classroom di Sekolah Dasar. https://doi.org/10.21070/picecrs.v2i1.2452

Roehl, A., Reddy, S. L., \& Shannon, G. J. (2013). The Flipped Classroom: An Opportunity Students Through Active. 105(2), 44-49.

Teo, P. (2019). Learning , Culture and Social Interaction Teaching for the 21st century: A case for dialogic pedagogy. 21(January), 170-178. https://doi.org/10.1016/j.lcsi.2019.03.009

Tim, K., \& Widjajanti, C. (n.d.). Peningkatan Proses Pembelajaran Dan Penilaian Pembelajaran Abad 21 Dalam Meningkatkan Kualitas Pembelajaran SMK.

van Alten, D. C. D., Phielix, C., Janssen, J., \& Kester, L. (2019). Effects of flipping the classroom on learning outcomes and satisfaction: A meta-analysis. Educational Research Review, 28(November 2018), 1-18. https://doi.org/10.1016/j.edurev.2019.05.003

Wijoyo, A. (2010). PENGARUH HASIL BELAJAR SISWA DENGAN MENGGUNAKAN MULTI MEDIA.

Wulansari, R., Rusnayati, H., Saepuzaman, D., And, S. K., \& A, S. F. (2019). The influence of scientific creativity and critical worksheets ( SCCW ) on creative thinking skills and critical scientific as well as students cognitive abilities on project-based learning work and energy concepts The influence of scientific creativity. https://doi.org/10.1088/1742-6596/1280/5/052039 
Yamarik, S. (2019). Flipping the classroom and student learning outcomes: Evidence from an international economics course. International Review of Economics Education, 31(September 2018), 100163. https://doi.org/10.1016/j.iree.2019.100163

Yasin, R. N. T. F. (n.d.). Pemanfaatan Flipped Classroom Berbasis Rumah Belajar | Blog Rumah Belajar. Retrieved March 24, 2020, from http://pena.belajar.kemdikbud.go.id/2019/10/pemanfaatan-flipped-classroomberbasis-rumah-belajar/ 